\title{
Epigenetic effect of testosterone in the behavior of C. elegans. A clue to explain androgen-dependent autistic traits?
}

\section{Mar Gámez-Del-Estal, Israel Contreras, Rocío Prieto-Pérez and Manuel Ruiz-Rubio*}

Departamento de Genética, Universidad de Córdoba, Hospital Universitario Reina Sofía, Instituto Maimónides de Investigación Biomédica de Córdoba, Córdoba, Spain

\section{Edited by:}

Hansen Wang, University of

Toronto, Canada

Reviewed by:

Firas H. Kobeissy, University of Florida, USA

Bice Chini, Consiglio Nazionale delle Ricerche CNR, Italy

*Correspondence:

Manuel Ruiz-Rubio, Departamento de Genética, Universidad de Córdoba, Campus de Rabanales, Edificio Gregor Mendel C-5, 14071 Córdoba, Spain

e-mail:ge1rurum@uco.es
Current research indicates that the causes of autism spectrum disorders (ASDs) are multifactorial and include both genetic and environmental factors. To date, several works have associated ASDs with mutations in genes that encode proteins involved in neuronal synapses; however other factors and the way they can interact with the development of the nervous system remain largely unknown. Some studies have established a direct relationship between risk for ASDs and the exposure of the fetus to high testosterone levels during the prenatal stage. In this work, in order to explain possible mechanisms by which this androgenic hormone may interact with the nervous system, $C$. elegans was used as an experimental model. We observed that testosterone was able to alter the behavioral pattern of the worm, including the gentle touch response and the pharyngeal pumping rate. This impairment of the behavior was abolished using specific RNAi against genes orthologous to the human androgen receptor gene. The effect of testosterone was eliminated in the nhr-69 (ok1926) deficient mutant, a putative ortholog of human AR gene, suggesting that this gene encodes a receptor able to interact with the hormone. On the other hand the testosterone effect remained in the gentle touch response during four generations in the absence of the hormone, indicating that some epigenetic mechanisms could be involved. Sodium butyrate, a histone deacetylase inhibitor, was able to abolish the effect of testosterone. In addition, the lasting effect of testosterone was eliminated after the dauer stage. These results suggest that testosterone may impair the nervous system function generating transgenerational epigenetic marks in the genome. This work may provide new paradigms for understanding biological mechanisms involved in ASDs traits.

Keywords: testosterone, Caenorhabditis elegans, epigenetics, gentle touch, pharyngeal pumping, nhr-69, nuclear hormone receptor, Autism spectrum disorders (ASDs)

\section{INTRODUCTION}

Autism spectrum disorders (ASDs) are diagnosed with a ratio of about four (male): one (female) across the whole spectrum (Baird et al., 2006), increasing to eight or nine to one in samples with higher functioning patients (Mandy et al., 2011). Some studies suggest that factors in neonatal development, such as those associated with male vs. female sexual development, may play a role in the etiology of some forms of this psychopathology (BaronCohen et al., 2003; Keller and Ruta, 2010). Thus, the prenatal environmental has been proposed as a key factor in the connection between autism and maleness. In 1973 it was observed that testosterone neonatal exposure controls male synaptic features in the rat hypothalamus (Raisman and Field, 1973). Subsequent studies have confirmed the effect of perinatal androgen hormone in the masculinization of brain morphology and function in rats, mice, and other mammalian animal models (Morrison and Rieder, 2004). In particular, the role of fetal testosterone has been highlighted as an influential hormone on cognitive and psychological brain development (Baron-Cohen et al., 2004). There are studies supporting this assumption indicating that testosterone exposure has permanent effects on brain development that may guide to male-differences, cognition and behavior respect to females (Cohen-Bendahan et al., 2005a,b; Hines, 2008; Auyeung et al., 2009; Whitehouse et al., 2012; Saenz and Alexander, 2013; Teatero and Netley, 2013). Therefore, it has been hypothesized that high levels of testosterone during early development might be a risk factor for ASDs. This idea is supported by several studies showing that testosterone levels are associated with autistic-like traits (Auyeung et al., 2009, 2010, 2012). Further, the importance of sex steroid related genes in ASDs is sustained by studies reporting associations between polymorphisms in genes involved in sex steroid synthesis/metabolism and ASDs and autistic-like traits (Chakrabarti et al., 2009; Henningsson et al., 2009; Zettergren et al., 2013). Children of mothers affected by hyperandrogenic polycystic ovary syndrome seem to have a higher risk for ASDs probably due to an unbalanced prenatal exposure to high levels of testosterone (Palomba et al., 2012). Finally, other results have shown association between the 
androgen receptor $(A R)$ gene and ASDs (Henningsson et al., 2009).

The human $A R$ gene, also known as NR3C4 (nuclear receptor subfamily 3 , group C, member 4 ), is a nuclear receptor activated by binding either one of the two androgenic hormones, testosterone, or dihydrotestosterone (Roy et al., 1999). The hormones bind in the cytoplasm to the receptor which then translocate into the nucleus to act upon transcription (Brinkmann, 2011). During androgen-dependent gene activation, histone demethylases are involved in the control of gene expression (Metzger et al., 2006). Specifically, phosphorylation of histone $\mathrm{H} 3$ at threonine 6 by protein kinase $\mathrm{C}$ beta-1 (PRKCB1) appears to prevent lysinespecific demethylase 1 from demethylating histone $\mathrm{H} 3$ at lysine 4 (H3K4) during androgen receptor-dependent gene activation (Metzger et al., 2010). The down-regulation of PRKCB1 in the temporal lobe has been correlated with ASDs (Lintas et al., 2009). Therefore, there is a strong current of opinion that considers the involvement of epigenetic mechanisms in autism (Mbadiwe and Millis, 2013).

Although studies in patients with ASDs have contributed significantly to the understanding of the pathogenesis of these diseases, many aspects of the molecular etiological basis remain unknown. Mammalian animal models have obvious advantages in order to translate them to humans, but their neuronal wiring maps are highly complex. The nematode Caenorhabditis elegans is an organism that has some exceptional characteristics for studying behavior and neurological diseases (Brenner, 1974; Calahorro and Ruiz-Rubio, 2011; Bessa et al., 2013). Up to the present time, only the neuronal wiring diagram of this nematode has been determined (White et al., 1986; Jarrell et al., 2012).

Steroid hormone receptors are included in the large superfamily of nuclear hormone receptors (NHRs), a group of transcription factors that bind lipophilic hormones (e.g., steroids, retinoids, thyroid hormones, bile-acid like hormones, and fatty acids) and they control the transcription of many target genes. C. elegans genome contains at least 284 predicted nuclear receptor gene (Gissendanner et al., 2004). Except the DAF-12 (dauer formation 12), which is the best understood steroid hormone receptor in C. elegans at the functional level (Galikova et al., 2010), the other NHRs are "orphan receptors" whose ligands have not been identified yet. On the other hand, the nematode requires dietary cholesterol during all developmental stages (Shim et al., 2002) and it has been reported that the worm has an ecdysteroid-like substance (Mercer et al., 1988). A more recent work showed that $C$. elegans contained several hormonal steroids, including pregnenolone ( $3 \beta$-hydroxy-pregn-5-en-20-one) and other pregnane and androstane derivatives. It has been found that pregnenolone increased the worm lifespan and influenced the regulation of aging. This study suggested that steroid hormones in C. elegans are synthesized from cholesterol since they are not detected in adults growing in cholesterol-deprived conditions (Broue et al., 2007). Other studies have described the effect of several vertebrate steroid sex hormones and synthetic hormones on C. elegans reproduction (Tominaga et al., 2003; Mimoto et al., 2007). For instance, testosterone at $5 \mu \mathrm{M}$ reduced fecundity and this effect was significantly higher after long-term exposure to this hormone (Tominaga et al., 2003).
The implication of specific genes in autism, in particular those encoding neuroligins and neurexins, has supported the use of this nematode in the study of ASDs (Calahorro et al., 2009; Hunter et al., 2010). Moreover, behaviors impaired in neuroligin (nlg-1) and neurexin (nrx-1) mutants of C. elegans were rescued by transgenic expression of human orthologous genes NLGN1 (Calahorro and Ruiz-Rubio, 2012), and alpha- and betaNRXN1 isoforms (Calahorro and Ruiz-Rubio, 2013), respectively. These observations revealed that human neuroligin and neurexin were functional in the nematode. In addition, methylphenidate (a dopamine reuptake inhibitor) and fluoxetine (a serotonin reuptake inhibitor), two drugs widely used for the treatment of behavioral disorders in humans, were able to restore behavioral impairments related to dopamine and serotonin pathways in neuroligin deficient mutants of C. elegans (Izquierdo et al., 2013).

One of the advantages of studying epigenetic mechanisms caused by testosterone in $C$. elegans could be the absence of DNA methylation in this organism (Bird, 2002), given that it links the possible epigenetic mechanisms exclusively to histone modifications. In this study, we observed that testosterone alters the mechanosensory response to gentle touch and the pharyngeal pumping rate of the worm. This effect of testosterone was abolished in the $n h r-69$ (ok1926) deficient mutant, a putative ortholog of human $A R$ gene, suggesting that this gene encodes a nuclear receptor able to interact with the hormone. The testosterone effect remained in the mechanosensory response during four generations in the absence of the hormone, indicating that some epigenetic mechanisms could be involved. These results suggest that testosterone may impair the nervous system functionality through a specific receptor generating transgenerational epigenetic marks in the genome.

\section{MATERIALS AND METHODS STRAINS AND MAINTENANCE}

All nematodes were grown and maintained at $20^{\circ} \mathrm{C}$ under standard conditions on Nematode Growth Medium (NGM) agar plates (Brenner, 1974). Table 1 shows the C. elegans strains used in this study. OP50 Escherichia coli strain was obtained from the Caenorhabditis Genetic Center (University of Minnesota, Minneapolis, MN, USA). For the bacterial feeding RNA interference assay, HT115 E. coli strain (DE3) with plasmid pL4440 carrying ORFs from different $C$. elegans genes were used. They were obtained from Julián Cerón, at the Bellvitge Institute for Biomedical Research (IDIBELL, Barcelona, Spain) and from Peter Askjaer at the Centro Andaluz de Biología del Desarrollo (CABD, Sevilla, Spain).

\section{BEHAVIORAL ASSAYS}

All the behavioral assays experiments were carried out at $20^{\circ}-24^{\circ} \mathrm{C}$ with $\mathrm{L} 4$ animals.

\section{Gentle touch response assay}

This assay was performed using an eyebrow hair attached to a toothpick. The phenotype was tested by stroking the worm ten times with the eyebrow hair alternating the anterior (just behind the pharynx) and posterior (just before the anus) part of the body. 
Table 1 | C. elegans strains used in this study.

\begin{tabular}{|c|c|c|}
\hline Strain name & Genotype & Source \\
\hline N2 & Wild type, DR subclone of CB original & $\mathrm{CGC}^{\mathrm{a}}$ \\
\hline TU3335 & $\begin{array}{l}\text { lin-15B(n744) X; uls57 [unc-119p::YFP } \\
+ \text { unc-119p::sid-1 + mec-6p:::mec-6] }\end{array}$ & CGC \\
\hline VC1127 & $n h r-126(g k 520) \mathrm{V}$ & CGC \\
\hline RB812 & fax-1 (ok624)X & CGC \\
\hline RB1578 & nhr-69 (ok1926) I & CGC \\
\hline VC1120 & $n h r-17(g k 509) X$ & CGC \\
\hline VC469 & $\begin{array}{l}+/ \text { szT1[lon-2(e678)] l; nhr-25(ok645)/ } \\
\text { szT1X }\end{array}$ & CGC \\
\hline STE68 & nhr-49(nr2041) I & CGC \\
\hline RB1592 & nhr-64(ok1957) I & CGC \\
\hline VC40185 & $n h r-226(g k 502851) \mathrm{V}$ & CGC \\
\hline CRR300 & nhr-69 (ok 1926) I & This study \\
\hline
\end{tabular}

${ }^{a}$ CGC: Caenorhabditis Genomic Center.

${ }^{b}$ After outcrossing RB1578 strain with N2 wild type two times.

A positive response causes the animal to move backward or forward respectively (Chalfie et al., 1985; Bounoutas and Chalfie, 2007).

\section{Pharyngeal pumping assay}

Pumping rates of individual worms were quantified by counting pharyngeal contractions. Individual L4 hermaphrodite grown on NGM plates seeded with OP50 were recorded, focusing on pharyngeal pumping. The video recording was followed by off-line analysis in slow motion.

\section{TESTOSTERONE ASSAYS}

Testosterone powder (Sigma-Aldrich, St. Louis, MO, USA) was diluted in $70 \%$ ethanol to obtain a stock concentration of $100 \mathrm{mM}$ and was added to NGM plates to get a final concentration of $0.01,0.1$, or $1 \mathrm{mM}$. In the majority of the experiments $1 \mathrm{mM}$ testosterone was used because the worms grew well and we could be sure that the hormone was not a limiting factor. Gravid adults were placed on seeded NGM control plates (with $0.7 \%$ ethanol) or seeded NGM with testosterone ( $1 \mathrm{mM}$ testosterone; $0.7 \%$ ethanol) and allowed to lay eggs to ensure that developing embryos were exposed to testosterone. The progeny were allowed to develop to the late L4 larval stage and then assayed for gentle touch response and pharyngeal pumping rate.

\section{BACTERIAL FEEDING RNA INTERFERENCE ASSAYS}

Wild type N2 Bristol and TU3335 C. elegans strains were used for RNAi experiments (Table 1). HT115 E. coli strain (DE3) with plasmid pL4440 carrying nhr-14 (T01B10.4), fax-1 (F56E3.4), nhr-111 (F44G3.9), nhr-236 (Y38F2AL.5), or mec-4 (T01C8.7) gene ORFs were provided by Julián Cerón at the Bellvitge Institute for Biomedical Research (IDIBELL, Barcelona, Spain). Worms were fed on standard agar plates supplemented with carbenicillin $(50 \mathrm{mg} / \mathrm{mL}-1)$ and $1 \mathrm{mM}$ IPTG to induce $d s R N A$ production. HT115 transformed with the empty pL4440, pL4440/unc-22 constructs (from Peter Askjaer at the Centro Andaluz de Biología del Desarrollo, CABD, Sevilla, Spain), were also used as controls in the experiments.

\section{SODIUM BUTYRATE ASSAYS}

Sodium butyrate (SB) powder (Sigma-Aldrich, St. Louis, MO, USA) was dissolved in water to obtain a stock concentration of $100 \mathrm{mM}$ and added to NGM plates to get a final concentration of $1 \mathrm{mM}$. Gravid adults coming from NGM testosterone plates ( $1 \mathrm{mM}$ testosterone; $0.7 \%$ ethanol) were placed or seeded NGM plates with testosterone and SB ( $1 \mathrm{mM}$ testosterone; $0.7 \%$ ethanol; $1 \mathrm{mM}$ sodium butyrate), and allowed to lay eggs. The progeny were allowed to develop to the late L4 larval stage, and then they were assayed for gentle touch response and pharyngeal pumping rate.

\section{DAUER STAGE ASSAYS}

Gravid adults were placed on NGM control plates ( $0.7 \%$ ethanol) or NGM testosterone plates ( $1 \mathrm{mM}$ testosterone; $0.7 \%$ ethanol) and allowed to lay eggs. The progeny were allowed to develop to the dauer larval stage (one month approximately). Then, dauer larval stage animals were placed on NGM plates seeded with OP50 bacteria and allowed to develop to the late L4 larval stage. Then, the animals were assayed for gentle touch response and pharyngeal pumping rate.

\section{TRANSGENERATIONAL ASSAY}

Gravid adults were placed on seeded NGM control plates $(0.7 \%$ ethanol) or seeded NGM testosterone plates ( $1 \mathrm{mM}$ testosterone; $0.7 \%$ ethanol) and allowed to lay eggs. The progeny were allowed to develop until the late L4 larval stage or to the gravid adult stage. The L4 animals were assayed for gentle touch response and pharyngeal pumping rate. The gravid adult animals were placed on seeded NGM plates without testosterone and allowed again to develop to the late L4 larval stage or to the gravid adult stage. Again, the L4 animals were assayed for gentle touch response and pharyngeal pumping rate, and the gravid adult animals were placed on seeded NGM plates without testosterone and allowed again to develop to the late L4 larval stage or to the gravid adult stage. This procedure was successively repeated to analyze the behavior in the following generations without testosterone.

\section{STATISTICAL ANALYSIS}

Comparisons shown in each experiment were done by One-Way ANOVA using Excel statistical tool.

\section{RESULTS}

\section{INFLUENCE OF TESTOSTERONE IN GENTLE TOUCH RESPONSE AND PHARYNGEAL PUMPING RATE}

When the nematode receives a tactile stimulus with an eyebrow hair in the anterior or posterior part of its body, it changes the direction of motion inducing movement back or forward respectively (Chalfie et al., 1985). Sensory cells of C. elegans translate mechanical inputs into ionic currents, which activate a neural circuit that drives a locomotory response (O'Hagan et al., 2005). The presence of different concentrations of testosterone induced the loss of a significant capability of the mechanosensory response with respect to the wild type strain (Figure 1A).

When C. elegans is stimulated repeatedly with an eyebrow hair (gentle touch), the stimulus fails to produce a response and the 
A

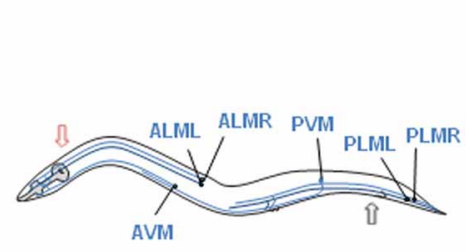

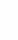

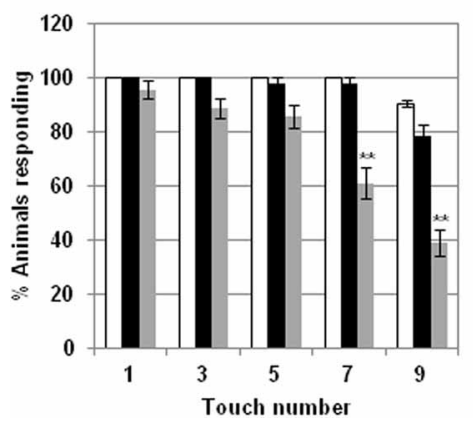

FIGURE 1 | Effect of testosterone on gentle touch response. (A) Left panel: diagram of 6 mechanosensory neurons involved in gentle touch response (blue) modified from Bounoutas and Chalfie (2007). In the gentle touch response animals were touched by stroking an eyebrow hair across the body just behind the pharynx (red arrow) for the anterior touch response, or just before the anus (black arrow) for the posterior touch response; Right panel: gentle touch response of N2 wild type strain was carried out either in the presence or absence of different concentration of testosterone $(0.01,0.1$, and $1 \mathrm{mM}$ ). Data were analyzed as number of positive responses to ten alternative gentle touches in the anterior and the posterior part of the body. (B) Testosterone alters the wild type gentle touch response. In the absence of the hormone N2 wild type strain responds five times consecutively to
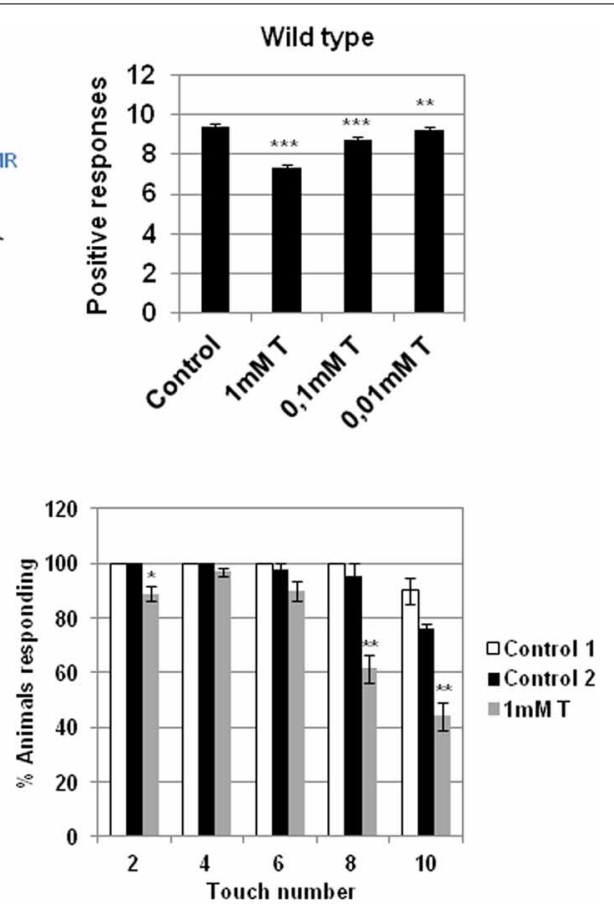

gentle touch in the anterior and posterior part of the body. In the presence of testosterone $(1 \mathrm{mM})$ the worm fails to respond significantly to the fourth and the fifth touch. Data were quantified as percentage of animals responding to ten alternative gentle touches in the anterior (left panel) and the posterior (right panel) part of the body (five each). At least three independent experiments were carried out (at least $10\llcorner 4$ worms per experiment). Bars represent the mean \pm SEM. Statistical significance was calculated by 1 -factor-ANOVA. Statistical $p$-values in (A): ${ }^{* *} p<0.01,{ }^{* *} p<0.001$ vs. "Control." Control: NGM + 0.7\% ETOH; T: NGM + 0.7\% ETOH + 1, 0.1, or $0.01 \mathrm{mM}$ testosterone. Statistical $p$-values in (B): ${ }^{* *} p<0.01,{ }^{*} p<0.05 \mathrm{vs}$. "Control 2." Control 1: NGM; Control 2: NGM + 0.7\% ETOH; $1 \mathrm{mM}$ T: $\mathrm{NGM}+0.7 \% \mathrm{ETOH}+1 \mathrm{mM}$ testosterone. animal become refractory (Chalfie et al., 1985). Figure 1B shows that in the absence of testosterone the wild type strain responds five times consecutively to gentle touch in the anterior and posterior parts of the body, whereas in the presence of testosterone the worms failed to respond mainly to the fourth and fifth touch.

We investigate whether testosterone had an effect in other complex behavior where motor control requires the interaction of the nervous system, muscles, and environment. The pharynx muscle movements of the nematode C. elegans is very well characterized (Bean et al., 2004). The worm feeding depends on a neuromuscular pump that connects the mouth to the intestine. The pharyngeal muscle takes bacteria and transports them through the gut. This is achieved with a combination of two actions, pumping and isthmus peristalsis. Pumping is the best understood and consists of a cycle of contraction and relaxation that sucks in liquid with suspended particles from the environment, and then expels the liquid trapping the solid particles. Pharyngeal muscle is capable of pumping without nervous system input, but during normal rapid feeding its timing is controlled by two pharyngeal motor neuron types (Avery and Horvitz, 1989). We examined the pharyngeal pumping in the absence and presence of $1 \mathrm{mM}$ testosterone and a significant reduction in the number of pumps count was observed in the presence of the hormone (Figure 2).

\section{ELEGANS ORTHOLOGOUS GENES OF THE HUMAN ANDROGEN RECEPTOR}

To test the presence of orthologous genes of the human androgen receptor gene $(A R)$ in the $C$. elegans genome, we carried out a BLAST search using the human AR receptor ligand-binding domain sequence (residues from 690 to 919) as a query, and as database the protein sequences of $C$. elegans (http://blast. ncbi.nlm.nih.gov/). Table 2 shows the results obtained from the BLAST analysis were the C. elegans proteins with homology are ordered respect to their E-values. The protein with the lowest E-value, that is, the best matching with the human AR receptor ligand-binding domain was NHR-69.

On the other hand the proteins obtained with the BLAST search were structurally compared with the human AR binding with testosterone (Table 3). The quality of the model was measured using QMEAN (Benkert et al., 2008, 2009). The QMEAN score 4 measures the global score of the whole model, reflecting the predicted model reliability range from 0 to 1 with higher 
values for better models. The highest reliability range was 0.48 for the FAX1 protein.

\section{CANDIDATE GENES FOR NUCLEAR HORMONE RECEPTOR INVOLVED IN THE RESPONSE TO TESTOSTERONE}

Feeding RNAi is efficient in almost all C. elegans cells except neurons (Timmons et al., 2001). Expression of SID-1, a

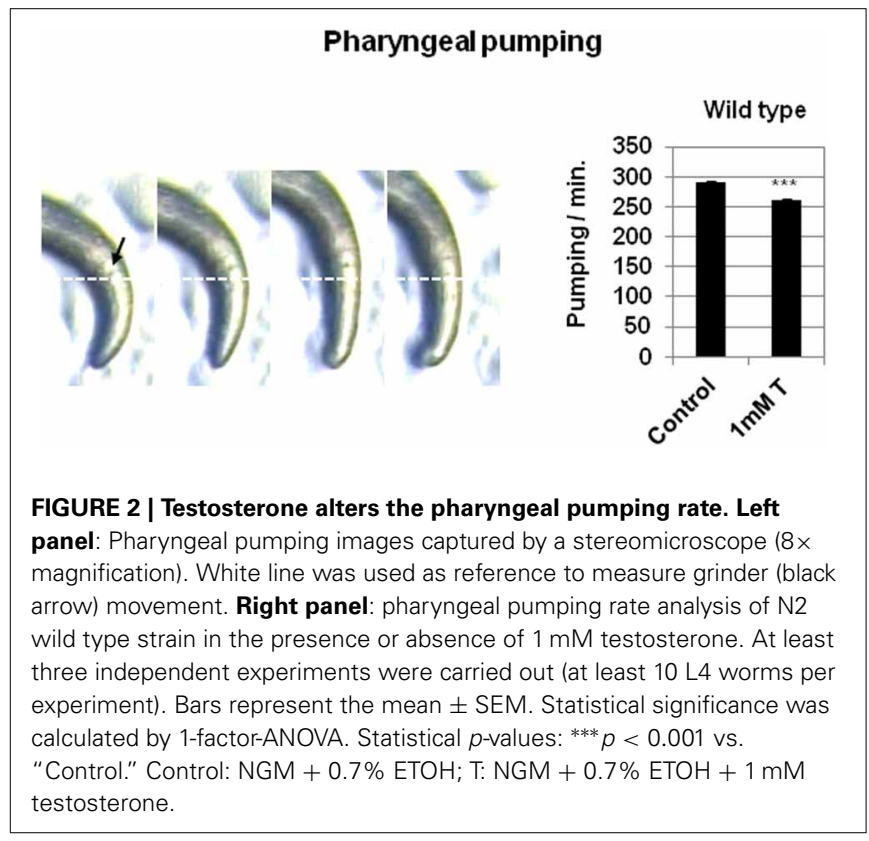

transmembrane protein from the worm is required for systemic RNA interference (RNAi) increases the response of neurons to double-stranded RNA delivered by feeding (Calixto et al., 2010). For that reason, we carried out RNAi feeding experiments with bacteria expressing specific ORFs of some C. elegans $n h r$-genes, in both the wild type $\mathrm{N} 2$ and the TU3335 strains, this latter expressing SID-1 in neurons.

Gentle touch response and pharyngeal pumping rate were analyzed in the absence and presence of testosterone (Figure 3 ). The results showed that $C$. elegans fed with bacteria containing plasmid pL4440 expressing dsRNA ORFs from fax-1, nhr-111, and $n h r-236$ (all orthologous of the human androgen receptor, see Table 1) showed a recovery in the response to the gentle touch (Figure 3A) and pharyngeal pumping (Figure 3B) assays in the presence of testosterone respect to control fed with bacteria with empty plasmid. This provides evidence for an in vivo function of $n h r$-genes in the response of C. elegans to testosterone.

Furthermore there was no significant difference between the knockdown strains and either wild type N2 or TU3335 strains without testosterone, an observation that contrasts with the response to gentle touch in worms fed with bacteria expressing dsRNA to mec-4, a gene expressed specifically in neurons and required for the gentle touch response (O'Hagan et al., 2005). These results suggest that the deficiency of $n h r$-genes in the effect of testosterone in gentle touch and pharyngeal pumping probably depends on the expression of these genes in different type of cells.

On the other hand the RNAi feeding experiment was also carry out with bacteria containing plasmid pL4440 expressing dsRNA ORFs from $n h r-14$, a C. elegans gene ortholog to human

Table 2 | Sequence comparison of the human androgen receptor ligand-binding domain (hAR-LBD) and the proteins in the $C$. elegans database*

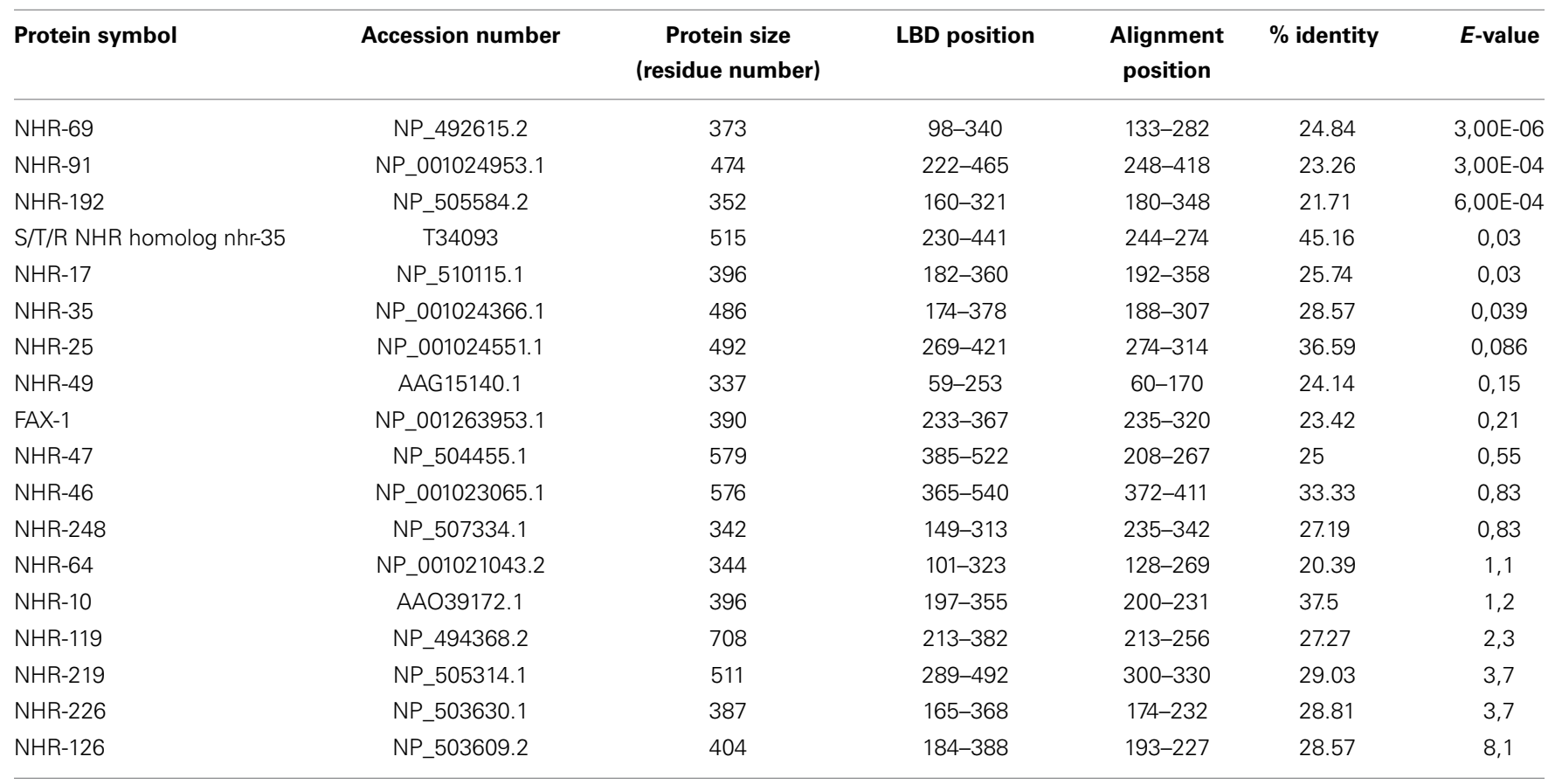

${ }^{*}$ http://blast.ncbi.nlm.nih.gov/

A selection of worm proteins with the highest identity values is shown. The results were obtained from BLAST analysis using human hAR-LBD (residues from 690 to 919) as a query. 
Table 3 | Putative genes from $\boldsymbol{C}$. elegans that could act as testosterone receptors.

\begin{tabular}{|c|c|c|c|c|}
\hline Protein symbol & $\begin{array}{c}\text { Accession } \\
\text { number }\end{array}$ & $\begin{array}{c}\text { Protein size } \\
\text { (residue } \\
\text { number) }\end{array}$ & $\begin{array}{c}\text { Modeled } \\
\text { residue } \\
\text { range }\end{array}$ & $\begin{array}{l}\text { QMEAN } \\
\text { score4 }\end{array}$ \\
\hline FAX-1 & NP_001263953.1 & 390 & $223-386$ & 0.48 \\
\hline NHR-119 & NP_494368.2 & 708 & $208-413$ & 0.463 \\
\hline NHR-192 & NP_505584.2 & 352 & $154-351$ & 0.451 \\
\hline NHR-69 & NP_492615.2 & 373 & 130-366 & 0.449 \\
\hline NHR-64 & NP_001021043.2 & 344 & $97-344$ & 0.442 \\
\hline NHR-126 & NP_503609.2 & 404 & $185-381$ & 0.426 \\
\hline NHR-35 & NP_001024366.1 & 486 & $177-384$ & 0.423 \\
\hline NHR-226 & NP_503630.1 & 387 & $166-362$ & 0.422 \\
\hline NHR-17 & NP_510115.1 & 396 & $178-390$ & 0.416 \\
\hline NHR-236 & CCD66972.1 & 283 & $115-273$ & 0.415 \\
\hline NHR-49 & AAG15140.1 & 337 & $37-256$ & 0.404 \\
\hline NHR-248 & NP_507334.1 & 342 & $120-341$ & 0.402 \\
\hline NHR-25 & NP_001024551.1 & 492 & $265-460$ & 0.4 \\
\hline NHR-91 & NP_001024953.1 & 474 & $234-453$ & 0.389 \\
\hline NHR-111 & CAB05521.2 & 311 & $141-307$ & 0.384 \\
\hline NHR-219 & NP_505314.1 & 511 & 290-484 & 0.378 \\
\hline NHR-46 & NP_001023065.1 & 576 & $360-574$ & 0.352 \\
\hline $\begin{array}{l}\text { S/T/R NHR } \\
\text { homolog nhr-35 }\end{array}$ & T34093 & 515 & $233-480$ & 0.278 \\
\hline NHR-47 & NP_504455.1 & 579 & $201-578$ & 0.269 \\
\hline
\end{tabular}

A selection of worm proteins with the highest identity values obtained from BLAST analysis using human hAR-LBD (residues from 690 to 919) vs. protein sequences of $C$. elegans database (Table 2), were structurally modeled by comparison with human androgen receptor in complex with testosterone. Swiss-Model Proteomic Serve was implemented. OMEANscore4 reflects the predicted model reliability ranging from 0 to 1 with higher values for better models.

estrogenic receptor (Mimoto et al., 2007). The sequence of the protein encoded by this gene presents a region with specific identity to the human androgen ligand-binding domain (12.17\%). The results obtained with $n h r-14$ knockdown animals were similar to those of fax-1, nhr-111, and $n h r-236$ knockdown ones (Figure 3). One explanation to this observation is an effect of cross-interference due to the high percentage of similarity between all these sequences. In fact, it has been demonstrate that siRNAs may cross-react with targets of limited sequence similarity (Jackson et al., 2003). Cross-interference seems to be very likely if there is $80 \%$ nucleotide identity over $200 \mathrm{bp}$ (Kamath and Ahringer, 2003).

\section{NHR-69 A PUTATIVE TESTOSTERONE RECEPTOR IN C. ELEGANS}

With the objective of finding genes able to function as a testosterone receptor, we carried out a screening for testosterone response in different mutant strains (Table 1) with deletions in genes orthologous of human $A R$. Figure 4A shows the effect of testosterone of these mutants on gentle touch response. Only the strain having a deletion in the gene $n h r-69$ did not show response to testosterone. To further confirm this observation, the mutant strain nhr-69 (ok1926) was out-crossed to clean its genome of undesired mutations, and then assayed again with testosterone

\section{A Gentle touch}

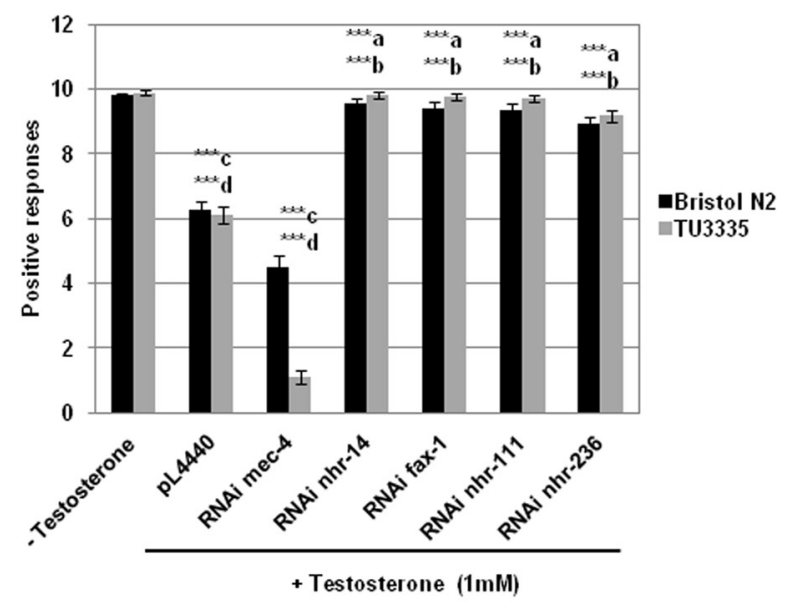

B Pharyngeal pumping

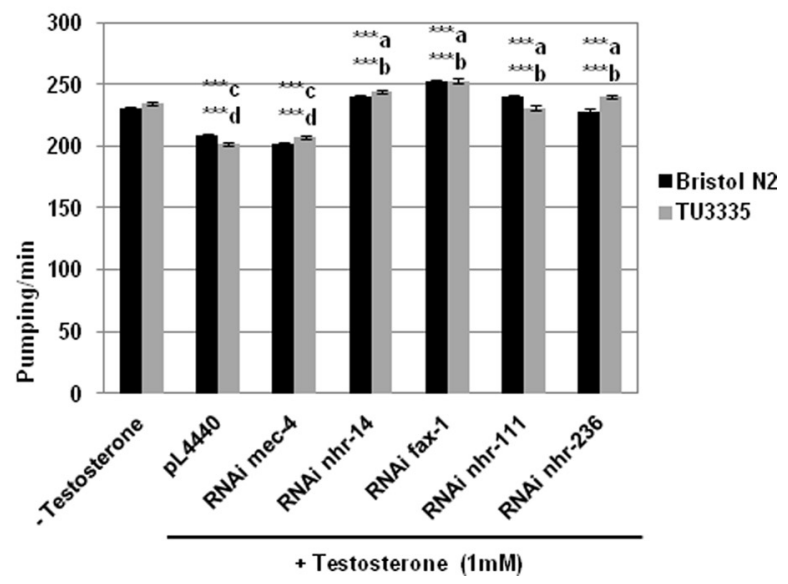

FIGURE 3 | RNAi feeding against genes from $C$. elegans. orthologous to human androgen and estrogen receptors abolishes the effect of testosterone in the behavior of $\boldsymbol{C}$. elegans. Bristol N2 and TU3335

$\left(P_{\text {unc-119 }}\right.$ sid -1$)$ strains were fed with bacteria carrying the $\mathrm{pL} 4440$ vector with different RNAi ORFs of mec-4, nhr-14, fax-1, nhr-111, and nhr-236 genes, or with the empty vector. Gentle touch response (A) and pharyngeal pumping rate $\mathbf{( B )}$ were quantified in the presence or absence of $1 \mathrm{mM}$ testosterone. At least three independent experiments were carried out (at least $10\llcorner 4$ worms per experiment). Bars represent the mean $\pm \mathrm{SEM}$. Statistical significance was calculated by 1-factor-ANOVA. Statistical p-values: ***a,b $p<0.001$ vs. "pL4440 empty vector" for N2 and TU3335 strains respectively; ${ }^{* * *} \mathrm{c}, \mathrm{d} p<0.001$ vs. "-Testosterone" for N2 and TU3335 strains respectively. - Testosterone: NGM + 0.7\% ETOH; +Testosterone: NGM + 0.7\% ETOH + $1 \mathrm{mM}$ testosterone.

respect of gentle touch response and pharyngeal pumping rate. The results shown in Figure 4B confirmed that mutant nhr-69 (ok1926) lost the capability to respond to testosterone in both behavioral assays.

\section{TRANSGENERATIONAL EPIGENETIC INHERITANCE OF IMPAIRED GENTLE TOUCH RESPONSE INDUCED BY TESTOSTERONE}

Steroid hormones can induce epigenetic chromatin modifications, including covalent changes of histone proteins, bringing 


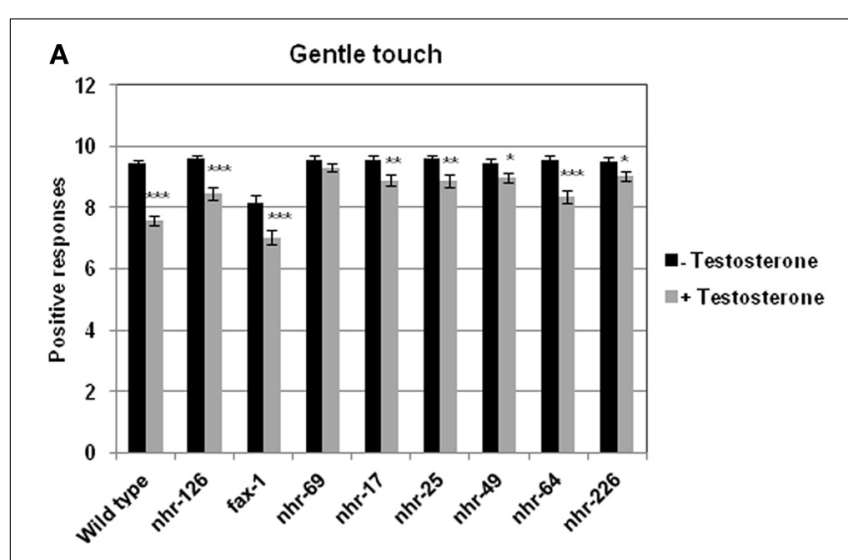$$
\text { B }
$$
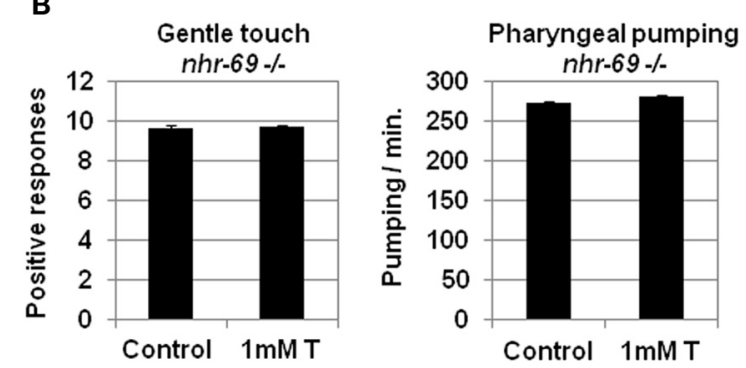

FIGURE 4 | Screening for testosterone response in different $\boldsymbol{C}$. elegans strains harboring deletions in genes orthologous of human androgen receptor. (A) Quantitative assays for gentle touch response were carried out in different strain of $C$. elegans defective in genes orthologous to human AR. (B) Touch sensitivity (left panel) and pharyngeal pumping rate (right panel) were quantified in $n h r-69$ (ok 1926) defective mutant strain (outcrossed $2 \times$ ). At least three independent experiments were carried out (at least $10 \mathrm{~L} 4$ worms per experiment). Bars represent the mean $\pm \mathrm{SEM}$. Statistical significance was calculated by 1 -factor-ANOVA. Statistical $p$-values in (A): ${ }^{*} p<0.05,{ }^{* *} p<0.01,{ }^{* * *} p<0.001$ vs. "Wild type + Testosterone". -Testosterone: NGM + 0.7\% ETOH; + Testosterone: NGM + $0.7 \% \mathrm{ETOH}+1 \mathrm{mM}$ testosterone. Statistical $p$-values in (B): not significant ( $p>0.05)$ vs. "Control." Control: NGM + 0.7\% ETOH; $1 \mathrm{mM} \mathrm{T:} \mathrm{NGM} \mathrm{+}$ $0.7 \% \mathrm{ETOH}+1 \mathrm{mM}$ testosterone.

long-lasting adjustments in gene expression in cancer cell lines and peripheral tissues (Ruiz-Cortes et al., 2005; Zhu et al., 2008). There are evidences of epigenetic action of neonatal testosterone in brain masculinization in mice (Murray et al., 2009).

The possible epigenetic changes originated by testosterone in the worm could not be due to DNA methylation, since C. elegans has not a predictable DNA methyltransferase in its genome neither 5-methyl cytosine $(5 \mathrm{mC})$ in its DNA (Bird, 2002). This suggests that other mechanisms has to be involved, most likely changes in chromatin histones. Indeed, it has been previously demonstrated that acute administration of sodium butyrate (SB) inhibits histone deacetylase in several organisms, including C. elegans (Catoire et al., 2008; Zhang et al., 2009), Drosophila (Tie et al., 2009), mammalian cells (Candido et al., 1978; Catoire et al., 2008) and even Saccharomyces cerevisiae (Yu et al., 2005) and plants (Chua et al., 2003). Therefore, to determine the possibility of the existence of epigenetic mechanisms induced by testosterone in the worm, we studied whether the histone deacetylase inhibitor SB had any effect on the results observed in the behavior associated to the steroid hormone action. Acute administration of $\mathrm{SB}$ resulted in marked increase in acetylation of histone $\mathrm{H} 3$ lysine 14 and histone $\mathrm{H} 4$ lysine 8 in specific tissues of mice (Itzhak et al., 2013). Figure 5A shows that SB (1 mM) abolishes the effect of testosterone on gentle touch response and pharyngeal pumping rate in C. elegans.

To determine whether the testosterone was able to induced epigenetic changes in behavior that were transgenerationally inherited, we studied its action on gentle touch response and pharyngeal pumping over several generations in the absence of the hormone. The results presented in Figure 5B shows that in the case of gentle touch response the effect could still extend in the four subsequent generations. However the reduction of the pharyngeal pumping rate disappeared just in the next generation.

There are mechanisms of reprogramming which are able of erasing epigenetic signatures typified by DNA methylation or histone modification (Apostolou and Hochedlinger, 2013). The life expectancy of $C$. elegans is approximately 2 weeks. However, in conditions of starvation, the developing larvae can adopt an alternative form, called the dauer stage. In this period the worm does not feed and is almost metabolically inactive (Fielenbach and Antebi, 2008). Dauer larva can survive for several months, and prolong the life span of the worm until 12 times more. The observations that the aging clock can be paused in the C. elegans dauer stage and reversed by environmental factors, suggest that the causes should be epigenetic mechanisms: on the one hand, blocking the gene expression in the dauer stage by epigenetic marks, and on the other hand reprogramming the metabolism and erasing these marks. For this reason it was possible that the dauer stage, could lead to the removing the epigenetic signals caused by testosterone. As seen in Figure 5C, when the worms were maintained on testosterone until dauer stage, and then growing on plates without the hormone, the gentle touch response and the pharyngeal pumping rate were similar to the control without testosterone.

\section{DISCUSSION}

In humans, testosterone performs critical functions from pregnancy to adolescence. An elevated level of testosterone during early human embryo development has been hypothesized to be a risk factor for ASDs. This idea is supported by several studies showing that high maternal testosterone levels are associated with autistic-like traits in the offspring. The mechanisms by which testosterone interacts with cells and carries out its effects on the development of the nervous system are poorly understood.

This study examines the effect of testosterone in two different behavioral traits of the nematode C. elegans, the response to gentle touch stimulation and the pharyngeal pumping rate. The presence of the hormone in the culture media induced the loss of a significant capacity of the reaction to gentle touch stimuli. In fact, it was observed that mechanic stimulation with an eyebrow hair led to a reduction in the response to the fourth and fifth touch of five consecutive touches in both the anterior and posterior parts of the body. Testosterone also induced a decrease in the pharyngeal pumping rate. These behaviors are mediated by distinct neural circuits, suggesting a broad impact of testosterone on neuronal synapse functionality. The way by which testosterone 


\section{A Sodium butyrate}

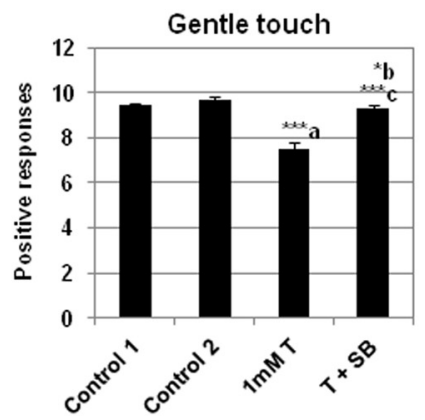

B Transgenerational assay

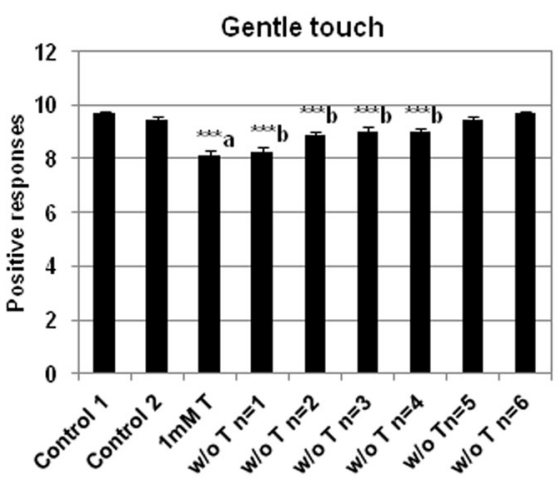

\section{Dauer}

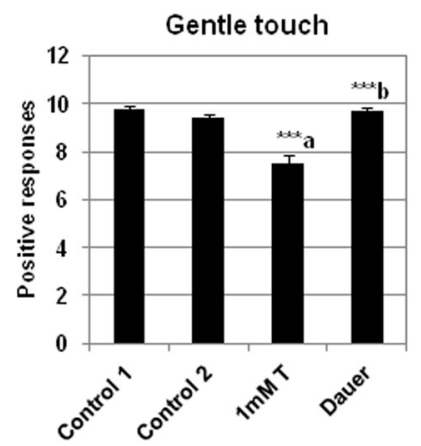

FIGURE 5 | Sodium butyrate and dauer stage abolish the effect of testosterone in gentle touch response and pharyngeal pumping rate. Transgenerational epigenetic inheritance of testosterone in C. elegans. (A) Sodium butyrate $(\mathrm{SB})(1 \mathrm{mM})$ recues impaired gentle touch response (left panel) and pharyngeal pumping rate (right panel) in N2 wild type strain growing in the presence of $1 \mathrm{mM}$ testosterone. (B) Transgenerational effect of the testosterone on gentle touch response (left panel) and pharyngeal pumping rate (right panel) in N2 wild type strain after several generations ( $n$ ) in the absence of testosterone ("w/o T"). (C) Analysis of the testosterone effect on gentle touch response (left panel) and pharyngeal pumping rate (right panel) in N2 wild type strain after dauer stage (Dauer). At least three independent experiments were carried out (at
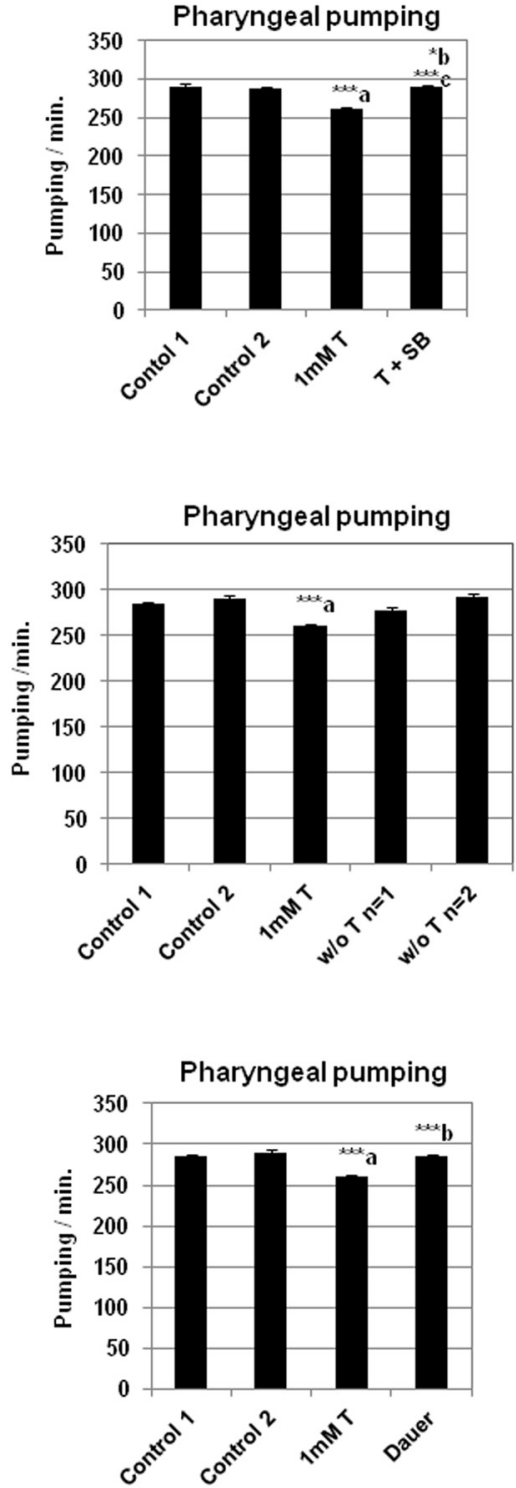

least 10 L4 worms per experiment). Bars represent the mean \pm SEM Statistical significance was calculated by 1 -factor-ANOVA. Statistical $p$-values in (A): ***a $p<0.001$ vs. "Control 1"; *b $p<0.05$ vs. "Control 2". ${ }^{* * *} \mathrm{c} p<0.001$ vs. "1 mM T". Control 1: NGM + 0.7\% ETOH; Control 2: $\mathrm{NGM}+0.7 \% \mathrm{ETOH}+1 \mathrm{mM}$ sodium butyrate; $1 \mathrm{mM}$ T: NGM + 0.7\% $\mathrm{ETOH}+1 \mathrm{mM}$ testosterone; T $+\mathrm{SB}: \mathrm{NGM}+0.7 \% \mathrm{ETOH}+1 \mathrm{mM}$ testosterone $+1 \mathrm{mM}$ sodium butyrate. Statistical $p$-values in (B): ***a $p<0.001$ vs. "Control 2"; ***b $p<0.001$ vs. "Control 1". Control 1: NGM; Control 2: $\mathrm{NGM}+0.7 \% \mathrm{ETOH} ; 1 \mathrm{mM} \mathrm{T}: \mathrm{NGM}+0.7 \% \mathrm{ETOH}+1 \mathrm{mM}$ testosterone. Statistical $p$-values in (C): ***a $p<0.001$ vs. "Control 2". ***b $p<0.001$ vs. "1 mM T". Control 1: NGM; Control 2: NGM + 0.7\% ETOH; $1 \mathrm{mM}$ T: NGM + 0.7\% ETOH + $1 \mathrm{mM}$ testosterone. affect the nervous system function is presumably by altering gene expression through a nuclear hormone receptor.

The genome of $C$. elegans contains at least 284 predicted nuclear receptor genes (Gissendanner et al., 2004). This number outnumbers those in mammals ( $\sim 50$ genes) (Zhang et al., 2004). A BLAST search with the human androgen receptor ligandbinding domain sequence against protein sequences of $C$. elegans resulted in several potential orthologous genes. Between them, 
NHR-69 presented the best matching sequence with the human AR receptor ligand-binding domain. Accordingly with this finding, we observed that the strain RB1578 with a deletion in the gene $n h r-69$ (ok1926) was insensitive to the effect of testosterone in both behavioral assays.

The gene $n h r-69$ was previously defined as being conserved between C. elegans and humans (Shaye and Greenwald, 2011). Furthermore, NHR-69 is predicted to function as a transcription factor that could activate or repress transcription in response to a hormonal signal (Gissendanner et al., 2004). A GFP-reporter gene for $n h r-69$ was expressed in pharynx, hypodermis, intestine, rectal epithelium, and uterine toroidal epithelial (Gissendanner et al., 2004). In addition a NHR-69::GFP fusion protein driven by the $n h r-69$ promoter was detected in the nucleus of the E8 intestinal precursor cells in developing embryos, expression that persisted until adulthood. In adults, expression was also detected in the ASI sensory neurons (gustatory-chemosensory, thermosensory), hypodermis, and tail neurons (Park et al., 2012).

Supporting the results observed in this work, previous in vitro experiments demonstrated the capacity of NHR-69 to bind both progesterone and testosterone (Mimoto et al., 2007). More recently it was found that NHR-69 partners with DAF-8. A model is proposed where this interaction represses the exp-2 gene that encodes a voltage-gated potassium channel. Low EXP-2 increases the secretion of the insulin-like peptide DAF-28 in ASI neurons (Park et al., 2012).

In respect of insulin it has been shown that pan-neuronal expression of APL-1, the C. elegans ortholog of the human amyloid precursor protein, disrupts several behavioral traits of the nematode. All these behaviors require activity of the transforming growth factor beta (TGF-beta) signaling pathway and reduced activity of the insulin pathway (Ewald et al., 2012). This might explain, at least indirectly, some of the effect originated by testosterone in behavior, if the binding of NHR-69 to the hormone compete the binding to DAF-8, and therefore modify insulin secretion and the activity of the insulin pathway. It is known that age-dependent neuronal defects are regulated by insulin signaling pathway (Peng et al., 2011).

We also found that the effects of testosterone on behavior were eliminated in presence of the deacetylase inhibitor SB and after dauer stage. Both experimental conditions suggest possible epigenetic mechanisms. In the case of sodium butyrate it is known that inhibits histone deacetylation in mammalian culture cells (Candido et al., 1978) and increases histone acetylation in C. elegans (Zhang et al., 2009). More recently was shown that an acute administration of SB resulted in a marked increase in acetylation of histone $\mathrm{H} 3$ at lysine 14 and histone $\mathrm{H} 4$ at lysine 8 in specific tissues of mice (Itzhak et al., 2013). In respect of dauer larval stage it was demonstrated that transiently passed through this stage, post-dauer adults exhibited significant changes in gene expression profiles and chromatin states when compared with control adults (Hall et al., 2010), which suggests a mechanism of DNA-chromatin reprogramming able to erase epigenetic marks.

Interestingly, we observed that the effect of testosterone in the gentle touch response was maintained, in the absence of the hormone, in the four subsequent generations after the exposition to the steroid. This observation suggests that the epigenetic effects of testosterone can be inherited transgenerationally. However, the results in the gentle touch contrast with the observed in the pharyngeal pumping rate, where the reduction rate induced by testosterone disappears in the next generation.

The molecular mechanisms underlying transgeneracional epigenetic marks are insufficiently understood (Youngson and Whitelaw, 2008). Research in C. elegans has illustrated several cases of transgenerational epigenetic inheritance. For example, it has been reported that modified histones incorporated into the sex chromosomes during spermatogenesis persist for several cell divisions postfertilization (Bean et al., 2004). One possible explanation for the differences between the gentle touch response and pharyngeal pumping rate after the exposure to testosterone is that the removal of epigenetic marks between generations depends on their position in the genome. Regarding this idea, a recent study demonstrates that deficiencies in genes involved in the COMPASS complex can induce transgenerational inheritance of longevity (Greer et al., 2011). The COMPASS complex, conserved from yeast to humans, catalyzes the trimethylation of histone $\mathrm{H} 3$ at lysine 9 (H3K4me3). H3K4me3 histone marks are usually present at the promoters of actively transcribed genes (Barth and Imhof, 2010). But the most remarkable phenomenon was that genetically wild type descendants from ancestors with a mutation in the COMPASS complex still display extended lifespan until the third generation (Greer et al., 2011). Interestingly, the number of genes showing down differential regulation was 7820 and 1740 genes in P0 and F4 generations respectively, in respect of the wild type strain. This observation suggests that the transgenerationally inherited gene misexpression profile returned to normal at the next (F5) generation, suggesting that these phenotypes may be directly linked. Thus, in this case the H3K4me3 dearth would be replenished, but only progressively, at each generation, until the chromatin state near the key mediator genes responsible for the longevity phenotype could be completely reset (Benayoun and Brunet, 2012). A similar mechanism could explain the differences between the gentle touch response and pharyngeal pumping rate phenotypes in successive generations after the exposure to testosterone.

Other potential molecular mechanism underlying the transgenerational inheritance could be activated by the production and transmission of non-coding RNAs. The introduction of doublestranded RNA (dsRNA) triggered sequence-specific genetic interference (RNAi) that was transmitted to offspring with the single sperm and maintained for three or more generations (Grishok et al., 2000; Grishok, 2013 and references therein). To this respect, genomic analysis demonstrated a connection between RNAi, chromatin and transgenerational RNAi inheritance ( $\mathrm{Gu}$ et al., 2012). This work identified dsRNA-induced histone H3 lysine 9 trimethylation ( $\mathrm{H} 3 \mathrm{~K} 9 \mathrm{me} 3)$ marks at several loci in animals fed with dsRNA. These H3K9me3 marks were also present in the F1 and $\mathrm{F} 2$ progenies, and they could spread up to $11 \mathrm{~kb}$ away from the dsRNA trigger region ( $\mathrm{Gu}$ et al., 2012). On other hand, it was shown that a germline nuclear small RNA/chromatin pathway can maintain stable inheritance for many generations when triggered by a piwi-interacting RNA (piRNA)-dependent foreign RNA response (Ashe et al., 2012). There is a recent report that 
relates testosterone, epigenetic, and miRNA function (Morgan and Bale, 2011).

In conclusion, our results demonstrate that testosterone can influence the behavior of $C$. elegans. The hormone appears to act causing epigenetic marks that can be inherited transgenerationally. Due to the finding of a positive association between elevated levels of fetal testosterone and autistic traits in humans, these results found in the nematode may be relevant to the understanding of mechanisms by which the hormone may interact with the nervous system.

\section{ACKNOWLEDGMENTS}

We thank the Caenorhabditis Genetics Center, funded by the NIH National Center for Research Resources, for worm strains, and Julián Cerón, Peter Askjaer, and Antonio Miranda-Vizuete for sharing bacterial strains and plasmids. We are very grateful to Antonio Moreno-Herrera for critical reading and reviewing the manuscript and José Antonio Bárcena for his help in analyzing protein sequences. We also thank Fernando Calahorro and Patricia G. Izquierdo for helpful comments and advices in the laboratory. Comments from Encarna Alejandre and assistance from Isabel Caballero are sincerely acknowledged. The research work has been supported by grant number PI0197 from Consejería de Salud, Junta de Andalucía Spain, and ITC20111029 from CDTI (Centro para el Desarrollo Tecnológico Industrial), Spain.

\section{REFERENCES}

Apostolou, E., and Hochedlinger, K. (2013). Chromatin dynamics during cellular reprogramming. Nature 502, 462-471. doi: 10.1038/nature12749

Ashe, A., Sapetschnig, A., Weick, E. M., Mitchell, J., Bagijn, M. P., Cording, A. C., et al. (2012). piRNAs can trigger a multigenerational epigenetic memory in the germline of C. elegans. Cell 150, 88-99. doi: 10.1016/j.cell.2012.06.018

Auyeung, B., Ahluwalia, J., Thomson, L., Taylor, K., Hackett, G., O’Donnell, K. J., et al. (2012). Prenatal versus postnatal sex steroid hormone effects on autistic traits in children at 18 to 24 months of age. Mol. Autism 3, 17. doi: 10.1186/20402392-3-17

Auyeung, B., Baron-Cohen, S., Ashwin, E., Knickmeyer, R., Taylor, K., and Hackett, G. (2009). Fetal testosterone and autistic traits. Br. J. Psychol. 100, 1-22. doi: 10.1348/000712608X311731

Auyeung, B., Taylor, K., Hackett, G., and Baron-Cohen, S. (2010). Foetal testosterone and autistic traits in 18 to 24-month-old children. Mol. Autism 1:11. doi: 10.1186/2040-2392-1-11

Avery, L., and Horvitz, H. R. (1989). Pharyngeal pumping continues after laser killing of the pharyngeal nervous system of C. elegans. Neuron 3, 473-485. doi: 10.1016/0896-6273(89)90206-7

Baird, G., Simonoff, E., Pickles, A., Chandler, S., Loucas, T., Meldrum, D., et al. (2006). Prevalence of disorders of the autism spectrum in a population cohort of children in South Thames: the Special Needs and Autism Project (SNAP). Lancet 368, 210-215. doi: 10.1016/S0140-6736(06)69041-7

Baron-Cohen, S., Lutchmaya, S., and Knickmeyer, R. (2004). Prenatal Testosterone in Mind. Cambridge, MA: The MIT Press.

Baron-Cohen, S., Richler, J., Bisarya, D., Gurunathan, N., and Wheelwright, S. (2003). The systemizing quotient: an investigation of adults with Asperger syndrome or high-functioning autism, and normal sex differences. Philos. Trans. $R$. Soc. Lond. B Biol. Sci. 358, 361-374. doi: 10.1098/rstb.2002.1206

Barth, T. K., and Imhof, A. (2010). Fast signals and slow marks: the dynamics of histone modifications. Trends Biochem. Sci. 35, 618-626. doi: 10.1016/j.tibs.2010.05.006

Bean, C. J., Schaner, C. E., and Kelly, W. G. (2004). Meiotic pairing and imprinted $\mathrm{X}$ chromatin assembly in Caenorhabditis elegans. Nat. Genet. 36, 100-105. doi: $10.1038 / \mathrm{ng} 1283$

Benayoun, B. A., and Brunet, A. (2012). Epigenetic memory of longevity in Caenorhabditis elegans. Worm 1, 77-81. doi: 10.4161/worm.19157
Benkert, P., Kunzli, M., and Schwede, T. (2009). QMEAN server for protein model quality estimation. Nucleic Acids Res. 37, W510-W514. doi: 10.1093/nar/gkp322

Benkert, P., Tosatto, S. C., and Schomburg, D. (2008). QMEAN: a comprehensive scoring function for model quality assessment. Proteins 71, 261-277. doi: $10.1002 /$ prot. 21715

Bessa, C., Maciel, P., and Rodrigues, A. J. (2013). Using C. elegans to decipher the cellular and molecular mechanisms underlying neurodevelopmental disorders. Mol. Neurobiol. 48, 465-489. doi: 10.1007/s12035-013-8434-6

Bird, A. (2002). DNA methylation patterns and epigenetic memory. Genes Dev. 16, 6-21. doi: 10.1101/gad.947102

Bounoutas, A., and Chalfie, M. (2007). Touch sensitivity in Caenorhabditis elegans. Pflugers Arch. 454, 691-702. doi: 10.1007/s00424-006-0187-x

Brenner, S. (1974). The genetics of Caenorhabditis elegans. Genetics 77, 71-94.

Brinkmann, A. O. (2011). Molecular mechanisms of androgen action-a historical perspective. Methods Mol. Biol. 776, 3-24. doi: 10.1007/978-1-61779-243-4_1

Broue, F., Liere, P., Kenyon, C., and Baulieu, E. E. (2007). A steroid hormone that extends the lifespan of Caenorhabditis elegans. Aging Cell 6, 87-94. doi: 10.1111/j.1474-9726.2006.00268.x

Calahorro, F., Alejandre, E., and Ruiz-Rubio, M. (2009). Osmotic avoidance in Caenorhabditis elegans: synaptic function of two genes, orthologues of human NRXN1 and NLGN1, as candidates for autism. J. Vis. Exp. 34:e1616. doi: $10.3791 / 1616$

Calahorro, F., and Ruiz-Rubio, M. (2011). Caenorhabditis elegans as an experimental tool for the study of complex neurological diseases: Parkinson's disease, Alzheimer's disease and autism spectrum disorder. Invert. Neurosci. 11, 73-83. doi: 10.1007/s10158-011-0126-1

Calahorro, F., and Ruiz-Rubio, M. (2012). Functional phenotypic rescue of Caenorhabditis elegans neuroligin-deficient mutants by the human and rat NLGN1 genes. PLoS ONE 7:e39277. doi: 10.1371/journal.pone.0039277

Calahorro, F., and Ruiz-Rubio, M. (2013). Human alpha- and beta-NRXN1 isoforms rescue behavioral impairments of Caenorhabditis elegans neurexindeficient mutants. Genes Brain Behav. 12, 453-464. doi: 10.1111/gbb.12046

Calixto, A., Chelur, D., Topalidou, I., Chen, X., and Chalfie, M. (2010). Enhanced neuronal RNAi in C. elegans using SID-1. Nat. Methods 7, 554-559. doi: 10.1038/nmeth.1463

Candido, E. P., Reeves, R., and Davie, J. R. (1978). Sodium butyrate inhibits histone deacetylation in cultured cells. Cell 14, 105-113. doi: 10.1016/00928674(78)90305-7

Catoire, H., Pasco, M. Y., Abu-Baker, A., Holbert, S., Tourette, C., Brais, B., et al. (2008). Sirtuin inhibition protects from the polyalanine muscular dystrophy protein PABPN1. Hum. Mol. Genet. 17, 2108-2117. doi: 10.1093/hmg/ddn109

Chakrabarti, B., Dudbridge, F., Kent, L., Wheelwright, S., Hill-Cawthorne, G., Allison, C., et al. (2009). Genes related to sex steroids, neural growth, and socialemotional behavior are associated with autistic traits, empathy, and Asperger syndrome. Autism Res. 2, 157-177. doi: 10.1002/aur.80

Chalfie, M., Sulston, J. E., White, J. G., Southgate, E., Thomson, J. N., and Brenner, S. (1985). The neural circuit for touch sensitivity in Caenorhabditis elegans. J. Neurosci. 5, 956-964.

Chua, Y. L., Watson, L. A., and Gray, J. C. (2003). The transcriptional enhancer of the pea plastocyanin gene associates with the nuclear matrix and regulates gene expression through histone acetylation. Plant Cell 15, 1468-1479. doi: 10.1105/tpc.011825

Cohen-Bendahan, C. C., Buitelaar, J. K., van Goozen, S. H., Orlebeke, J. F., and Cohen-Kettenis, P. T. (2005a). Is there an effect of prenatal testosterone on aggression and other behavioral traits? A study comparing same-sex and opposite-sex twin girls. Horm. Behav. 47, 230-237. doi: 10.1016/j.yhbeh.2004.10.006

Cohen-Bendahan, C. C., van de Beek, C., and Berenbaum, S. A. (2005b). Prenatal sex hormone effects on child and adult sex-typed behavior: methods and findings. Neurosci. Biobehav. Rev. 29, 353-384. doi: 10.1016/j.neubiorev.2004.11.004

Ewald, C. Y., Cheng, R., Tolen, L., Shah, V., Gillani, A., Nasrin, A., et al. (2012) Pan-neuronal expression of APL-1, an APP-related protein, disrupts olfactory, gustatory, and touch plasticity in Caenorhabditis elegans. J. Neurosci. 32, 10156-10169. doi: 10.1523/JNEUROSCI.0495-12.2012

Fielenbach, N., and Antebi, A. (2008). C. elegans dauer formation and the molecular basis of plasticity. Genes Dev. 22, 2149-2165. doi: 10.1101/gad.1701508

Galikova, M., Klepsatel, P., Senti, G., and Flatt, T. (2010). Steroid hormone regulation of C. elegans and Drosophila aging and life history. Exp. Gerontol. 46, 141-147. doi: 10.1016/j.exger.2010.08.021 
Gissendanner, C. R., Crossgrove, K., Kraus, K. A., Maina, C. V., and Sluder, A. E. (2004). Expression and function of conserved nuclear receptor genes in Caenorhabditis elegans. Dev. Biol. 266, 399-416. doi: 10.1016/j.ydbio.2003.10.014

Greer, E. L., Maures, T. J., Ucar, D., Hauswirth, A. G., Mancini, E., Lim, J. P., et al. (2011). Transgenerational epigenetic inheritance of longevity in Caenorhabditis elegans. Nature 479, 365-371. doi: 10.1038/nature 10572

Grishok, A. (2013). Biology and mechanisms of short RNAs in Caenorhabditis elegans. Adv. Genet. 83, 1-69. doi: 10.1016/B978-0-12-407675-4.00001-8

Grishok, A., Tabara, H., and Mello, C. C. (2000). Genetic requirements for inheritance of RNAi in C. elegans. Science 287, 2494-2497. doi: 10.1126/science.287.5462.2494

Gu, S. G., Pak, J., Guang, S., Maniar, J. M., Kennedy, S., and Fire, A. (2012). Amplification of siRNA in Caenorhabditis elegans generates a transgenerational sequence-targeted histone H3 lysine 9 methylation footprint. Nat. Genet. 44, 157-164. doi: 10.1038/ng.1039

Hall, S. E., Beverly, M., Russ, C., Nusbaum, C., and Sengupta, P. (2010). A cellular memory of developmental history generates phenotypic diversity in C. elegans. Curr. Biol. 20, 149-155. doi: 10.1016/j.cub.2009.11.035

Henningsson, S., Jonsson, L., Ljunggren, E., Westberg, L., Gillberg, C., Rastam, M., et al. (2009). Possible association between the androgen receptor gene and autism spectrum disorder. Psychoneuroendocrinology 34, 752-761. doi: 10.1016/j.psyneuen.2008.12.007

Hines, M. (2008). Early androgen influences on human neural and behavioural development. Early Hum. Dev. 84, 805-807. doi: 10.1016/j.earlhumdev.2008.09.006

Hunter, J. W., Mullen, G. P., McManus, J. R., Heatherly, J. M., Duke, A., and Rand, J. B. (2010). Neuroligin-deficient mutants of C. elegans have sensory processing deficits and are hypersensitive to oxidative stress and mercury toxicity. Dis. Model. Mech. 3, 366-376. doi: 10.1242/dmm.003442

Itzhak, Y., Liddie, S., and Anderson, K. L. (2013). Sodium butyrate-induced histone acetylation strengthens the expression of cocaine-associated contextual memory. Neurobiol. Learn. Mem. 102, 34-42. doi: 10.1016/j.nlm.2013. 03.007

Izquierdo, P. G., Calahorro, F., and Ruiz-Rubio, M. (2013). Neuroligin modulates the locomotory dopaminergic and serotonergic neuronal pathways of C. elegans. Neurogenetics 14, 233-242. doi: 10.1007/s10048-013-0377-6

Jackson, A. L., Bartz, S. R., Schelter, J., Kobayashi, S. V., Burchard, J., Mao, M., et al. (2003). Expression profiling reveals off-target gene regulation by RNAi. Nat. Biotechnol. 21, 635-637. doi: 10.1038/nbt831

Jarrell, T. A., Wang, Y., Bloniarz, A. E., Brittin, C. A., Xu, M., Thomson, J. N., et al. (2012). The connectome of a decision-making neural network. Science 337, 437-444. doi: 10.1126/science. 1221762

Kamath, R. S., and Ahringer, J. (2003). Genome-wide RNAi screening in Caenorhabditis elegans. Methods 30, 313-321. doi: 10.1016/S10462023(03)00050-1

Keller, F., and Ruta, L. (2010). "The male prevalence in autism spectrum disorders: hypotheses on its neurobiological basis," in The Neurochemical Basis of Autism: From Molecules to Minicolumns, ed G. J. Blatt (New York, NY: Springer), 13-28.

Lintas, C., Sacco, R., Garbett, K., Mirnics, K., Militerni, R., Bravaccio, C., et al. (2009). Involvement of the PRKCB1 gene in autistic disorder: significant genetic association and reduced neocortical gene expression. Mol. Psychiatry 14, 705-718. doi: 10.1038/mp.2008.21

Mandy, W., Charman, T., Gilmour, J., and Skuse, D. (2011). Toward specifying pervasive developmental disorder-not otherwise specified. Autism Res. 4, 121-131. doi: 10.1002/aur.178

Mbadiwe, T., and Millis, R. M. (2013). Epigenetics and autism. Autism Res. Treat. 2013:826156. doi: 10.1155/2013/826156

Mercer, J. G., Munn, A. E., and Rees, H. H. (1988). Caenorhabditis elegans: occurrence and metabolism of ecdysteroids in adults and dauer larvae. Comp. Biochem. Physiol. B 90, 261-267. doi: 10.1016/0305-0491(88)90070-3

Metzger, E., Imhof, A., Patel, D., Kahl, P., Hoffmeyer, K., Friedrichs, N., et al. (2010). Phosphorylation of histone H3T6 by PKCbeta(I) controls demethylation at histone H3K4. Nature 464, 792-796. doi: 10.1038/nature08839

Metzger, E., Wissmann, M., and Schule, R. (2006). Histone demethylation and androgen-dependent transcription. Curr. Opin. Genet. Dev. 16, 513-517. doi: 10.1016/j.gde.2006.08.013

Mimoto, A., Fujii, M., Usami, M., Shimamura, M., Hirabayashi, N., Kaneko, T., et al. (2007). Identification of an estrogenic hormone receptor in
Caenorhabditis elegans. Biochem. Biophys. Res. Commun. 364, 883-888. doi: 10.1016/j.bbrc.2007.10.089

Morgan, C. P., and Bale, T. L. (2011). Early prenatal stress epigenetically programs dysmasculinization in second-generation offspring via the paternal lineage. J. Neurosci. 31, 11748-11755. doi: 10.1523/JNEUROSCI.188711.2011

Morrison, C., and Rieder, C. L. (2004). Chromosome damage and progression into and through mitosis in vertebrates. DNA Repair (Amst.) 3, 1133-1139. doi: 10.1016/j.dnarep.2004.03.005

Murray, E. K., Hien, A., de Vries, G. J., and Forger, N. G. (2009). Epigenetic control of sexual differentiation of the bed nucleus of the stria terminalis. Endocrinology 150, 4241-4247. doi: 10.1210/en.2009-0458

O'Hagan, R., Chalfie, M., and Goodman, M. B. (2005). The MEC-4 DEG/ENaC channel of Caenorhabditis elegans touch receptor neurons transduces mechanical signals. Nat. Neurosci. 8, 43-50. doi: 10.1038/nn1362

Palomba, S., Marotta, R., Di Cello, A., Russo, T., Falbo, A., Orio, F., et al. (2012). Pervasive developmental disorders in children of hyperandrogenic women with polycystic ovary syndrome: a longitudinal case-control study. Clin. Endocrinol. (Oxf.) 77, 898-904. doi: 10.1111/j.1365-2265.2012. 04443.x

Park, D., Jones, K. L., Lee, H., Snutch, T. P., Taubert, S., and Riddle, D. L. (2012). Repression of a potassium channel by nuclear hormone receptor and TGF-beta signaling modulates insulin signaling in Caenorhabditis elegans. PLoS Genet. 8:e1002519. doi: 10.1371/journal.pgen.1002519

Peng, C. Y., Chen, C. H., Hsu, J. M., and Pan, C. L. (2011). C. elegans model of neuronal aging. Commun. Integr. Biol. 4, 696-698. doi: 10.4161/cib.4.6.17138

Raisman, G., and Field, P. M. (1973). Sexual dimorphism in the neuropil of the preoptic area of the rat and its dependence on neonatal androgen. Brain Res. 54, 1-29. doi: 10.1016/0006-8993(73)90030-9

Roy, A. K., Lavrovsky, Y., Song, C. S., Chen, S., Jung, M. H., Velu, N. K., et al. (1999). Regulation of androgen action. Vitam. Horm. 55, 309-352. doi: 10.1016/S00836729(08)60938-3

Ruiz-Cortes, Z. T., Kimmins, S., Monaco, L., Burns, K. H., Sassone-Corsi, P., and Murphy, B. D. (2005). Estrogen mediates phosphorylation of histone $\mathrm{H} 3$ in ovarian follicle and mammary epithelial tumor cells via the mitotic kinase, Aurora B. Mol. Endocrinol. 19, 2991-3000. doi: 10.1210/me.20 04-0441

Saenz, J., and Alexander, G. M. (2013). Postnatal testosterone levels and disorder relevant behavior in the second year of life. Biol. Psychol. 94, 152-159. doi: 10.1016/j.biopsycho.2013.05.011

Shaye, D. D., and Greenwald, I. (2011). OrthoList: a compendium of C. elegans genes with human orthologs. PLoS ONE 6:e20085. doi: 10.1371/journal.pone.0020085

Shim, Y. H., Chun, J. H., Lee, E. Y., and Paik, Y. K. (2002). Role of cholesterol in germ-line development of Caenorhabditis elegans. Mol. Reprod. Dev. 61, 358-366. doi: 10.1002/mrd.10099

Teatero, M. L., and Netley, C. (2013). A critical review of the research on the extreme male brain theory and digit ratio (2D:4D). J. Autism Dev. Disord. 43, 2664-2676. doi: 10.1007/s10803-013-1819-6

Tie, F., Banerjee, R., Stratton, C. A., Prasad-Sinha, J., Stepanik, V., Zlobin, A., et al. (2009). CBP-mediated acetylation of histone H3 lysine 27 antagonizes Drosophila polycomb silencing. Development 136, 3131-3141. doi: 10.1242/dev.037127

Timmons, L., Court, D. L., and Fire, A. (2001). Ingestion of bacterially expressed dsRNAs can produce specific and potent genetic interference in Caenorhabditis elegans. Gene 263, 103-112. doi: 10.1016/S0378-1119(00)00579-5

Tominaga, N., Ura, K., Kawakami, M., Kawaguchi, T., Kohra, S., Mitsui, Y., et al. (2003). Caenorhabditis elegans responses to specific steroid hormones. J. Health Sci. 49, 28-33. doi: 10.1248/jhs.49.28

White, J. G., Southgate, E., Thomson, J. N., and Brenner, S. (1986). The structure of the nervous system of the nematode Caenorhabditis elegans. Philos. Trans. R. Soc. Lond. B Biol. Sci. 314, 1-340. doi: 10.1098/rstb.1986.0056

Whitehouse, A. J., Mattes, E., Maybery, M. T., Dissanayake, C., Sawyer, M., Jones, R. M., et al. (2012). Perinatal testosterone exposure and autistic-like traits in the general population: a longitudinal pregnancy-cohort study. J. Neurodev. Disord. 4, 25. doi: 10.1186/1866-1955-4-25

Youngson, N. A., and Whitelaw, E. (2008). Transgenerational epigenetic effects. Annu. Rev. Genomics Hum. Genet. 9, 233-257. doi: 10.1146/annurev.genom.9.081307.164445 
Yu, Y., Teng, Y., Liu, H., Reed, S. H., and Waters, R. (2005). UV irradiation stimulates histone acetylation and chromatin remodeling at a repressed yeast locus. Proc. Natl. Acad. Sci. U.S.A. 102, 8650-8655. doi: 10.1073/pnas.0501458102

Zettergren, A., Jonsson, L., Johansson, D., Melke, J., Lundstrom, S., Anckarsater, H., et al. (2013). Associations between polymorphisms in sex steroid related genes and autistic-like traits. Psychoneuroendocrinology 38, 2575-2584. doi: 10.1016/j.psyneuen.2013.06.004

Zhang, M., Poplawski, M., Yen, K., Cheng, H., Bloss, E., Zhu, X., et al. (2009). Role of CBP and SATB-1 in aging, dietary restriction, and insulin-like signaling. PLoS Biol. 7:e1000245. doi: 10.1371/journal.pbio.1000245

Zhang, Z., Burch, P. E., Cooney, A. J., Lanz, R. B., Pereira, F. A., Wu, J., et al. (2004). Genomic analysis of the nuclear receptor family: new insights into structure, regulation, and evolution from the rat genome. Genome Res. 14, 580-590. doi: $10.1101 /$ gr.2160004

Zhu, X., Asa, S. L., and Ezzat, S. (2008). Fibroblast growth factor 2 and estrogen control the balance of histone 3 modifications targeting MAGE-A3 in pituitary neoplasia. Clin. Cancer Res. 14, 1984-1996. doi: 10.1158/1078-0432.CCR07-2003
Conflict of Interest Statement: The authors declare that the research was conducted in the absence of any commercial or financial relationships that could be construed as a potential conflict of interest.

Received: 23 December 2013; accepted: 17 February 2014; published online: 04 March 2014.

Citation: Gámez-Del-Estal MM, Contreras I, Prieto-Pérez $R$ and Ruiz-Rubio $M$ (2014) Epigenetic effect of testosterone in the behavior of C. elegans. A clue to explain androgen-dependent autistic traits? Front. Cell. Neurosci. 8:69. doi: 10.3389/fncel. 2014.00069

This article was submitted to the journal Frontiers in Cellular Neuroscience.

Copyright (c) 2014 Gámez-Del-Estal, Contreras, Prieto-Pérez and Ruiz-Rubio. This is an open-access article distributed under the terms of the Creative Commons Attribution License (CC BY). The use, distribution or reproduction in other forums is permitted, provided the original author $(s)$ or licensor are credited and that the original publication in this journal is cited, in accordance with accepted academic practice. No use, distribution or reproduction is permitted which does not comply with these terms. 